\title{
Drivers of bird diversity in an understudied African centre of endemism: The Angolan Central Escarpment Forest
}

Aimy Cáceres* ${ }^{1,5}$, Martim Melo ${ }^{1,5,6}$, Jos Barlow ${ }^{2}$, Ricardo Faustino de Lima ${ }^{3,7}$ and Michael S.L. Mills ${ }^{4,6}$

${ }^{1}$ Centro de Investigação em Biodiversidade e Recursos Genéticos, Universidade do Porto, InBIO Laboratório Associado, Campus Agrário de Vairão, Rua Padre Armando Quintas, 4485-661 Vairão, Portugal.

${ }^{2}$ Lancaster Environment Centre, Lancaster University, Lancaster, UK.

${ }^{3}$ Centre for Ecology, Evolution and Environmental Changes (Ce3C), Faculdade de Ciências, Universidade de Lisboa, Lisboa, Portugal.

${ }^{4}$ A.P. Leventis Ornithological Research Institute, University of Jos, Plateau State, Nigeria ${ }^{5}$ Instituto Superior de Ciências da Educação de Huíla, Rua Sarmento Rodrigues s/n, Lubango, Angola.

${ }^{6}$ DST/NRF Centre of Excellence at the Percy FitzPatrick Institute, University of Cape Town, Rondebosch, South Africa.

${ }^{7}$ Associação Monte Pico, Monte Café, São Tomé, Democratic Republic of São Tomé and Príncipe.

*Corresponding author: aimycp@gmail.com 


\section{Summary}

2 Natural habitats are being rapidly lost due to human activities. It is therefore vital to understand

3 how these activities influence biodiversity so that suitable guidelines can be established for

4 conservation. This is particularly important in understudied, high biodiversity, areas such as the

5 Angolan Escarpment. Here we examine which habitat characteristics drive bird diversity and

6 endemic species presence at Kumbira Forest, a key site in the Central Escarpment Forest. Bird

7 diversity was sampled by $10 \mathrm{~min}$ bird point counts, whereas habitat characteristics were measured

8 by a combination of ground-based vegetation surveys and remotely sensed data modelling of

9 Landsat images. GLM, multi-model inference and model averaging were used to determine the

10 most important variables driving species richness and the presence of endemics. The remote

11 sensing variables performed poorly in predicting presence of Red-crested Turaco and Gabela

12 Bushshrike but they contributed significantly to explain species richness and Gabela Akalat

13 presence, both of which were associated with greater canopy cover. Liana density and elevation

14 were also important explanatory variables in certain cases. Conservation actions at Kumbira

15 should focus on increasing canopy cover and maintaining forest integrity (as measured by liana

16 density), as these actions are likely to have the most positive outcomes for the avifauna.

18 Keywords: Angola; endemics; generalized linear model; Kumbira; model averaging

20 Introduction

21 Habitat loss due to human activities is the most important threat to biodiversity (Brooks et al.,

22 2002) and the main cause of population declines and species extinctions in birds (Stattersfield

23 and Capper, 2000). This is especially significant in the tropics, where almost 70 percent of global 
24 biodiversity is concentrated (Bradshaw et al., 2009) and human impacts are increasing at an

25 accelerating pace (Cincotta et al., 2000). Despite primary forests being irreplaceable for

26 maintaining tropical biodiversity (Gibson et al., 2011), modified landscapes such as secondary

27 growth and agroforestry systems can also hold important biodiversity and connect core areas for

28 conservation (Schulze et al., 2004, Gove et al., 2008, Cáceres et al., 2015). Therefore, to

29 implement successful conservation strategies it is important to assess biodiversity in human-

30 modified landscapes (Chazdon et al., 2009, Gardner et al., 2009), and to identify the key factors

31 influencing biodiversity in these landscapes. This is especially the case for extinction-prone

32 species, such as those that are range-restricted or especially sensitive to human activities.

African biodiversity is globally important but extremely understudied (Norris et al., 2010,

34 Gardner et al., 2010, Gibson et al., 2011). This is particularly true for Angola: while it is

35 considered one of the most biodiverse countries of Africa due its location at the confluence of

36 five different biomes, it is very poorly known as a result of almost 30 years of armed conflict

37 (Huntley, 1974, USAID, 2008). The Escarpment Forest constitutes one of the most important

38 areas for biodiversity in the country, although it could not be designated as a "biodiversity

39 hotspot' due to the lack of information available at the time of the 'hotspot' analyses (Myers et

40 al., 2000). In the case of birds, arguably the best-studied taxonomic group in Angola, these

41 forests are of key conservation importance. The Escarpment Forest is an important evolutionary

42 hotspot (Hall, 1960) where most of the endemic bird species of Angola are found, and it is the

43 most important habitat of the Western Angola Endemic Bird Area, the only centre of bird

44 endemism in the country. Because no protected area is located within this habitat, it has been

45 identified as a critical conservation priority for birds, not only for Angola (Dean, 2001, BirdLife

46 International, 2015a) but for Africa as a whole (Collar and Stuart, 1988). 
By the 1960s it was estimated that 95 percent of the original forests had been converted to

48 shade-coffee plantations, which left the high canopy trees intact (Hawkins, 1993). During the

49 civil war (1975-2002) these plantations were abandoned, allowing forest habitats to recover

50 (Ryan et al., 2004, Sekercioglu and Riley, 2005). The end of the war led to the migration of

51 human populations back to rural areas like the Central Escarpment Forest, and since then slash-

52 and-burn agriculture and logging have become major threats to these forests (Mills, 2010,

53 Cáceres et al., 2015). It is therefore important to understand the impacts that these human

54 activities are having on the forests, such as how they are affecting habitat characteristics, which

55 in turn influence bird diversity and the distribution and abundance of threatened endemics.

56 The main aim of this study was to understand the environmental drivers influencing bird

57 diversity at Kumbira Forest, a key site for threatened endemic birds in Angola (Mills, 2010).

58 Because conservation planning will be most effective if it is based on regional-scale species

59 distribution models, we first assess if variables obtained through remote sensing techniques

60 contribute to explain bird diversity in Kumbira. Then, we use locally collected ground variables

61 obtained through vegetation surveys to model species richness and presence of endemic birds.

62 Finally, we propose conservation guidelines based on the results.

64 Methods

65 Study Area

66 Kumbira Forest is the most representative and important site for the conservation of threatened

67 endemic birds of the Angolan Central Escarpment. It holds significant populations of four of the

68 five threatened endemics of this region, namely of the Endangered Gabela Bushshrike Laniarius

69 amboimensis, Gabela Akalat Sheppardia gabela and Pulitzer's Longbill Macrosphenus pulitzeri, 
70 and Near Threatened Monteiro's Bushshrike Malaconous monteiri (Data Deficient at the time

71 that field work was done). Gabela Akalat is the most range-restricted of the Angolan endemics

72 with an estimated range of only $c .650 \mathrm{~km}^{2}$, although it can be locally common, as it is at

73 Kumbira. Gabela Bushshrike has a wider distribution $\left(c .1800 \mathrm{~km}^{2}\right)$, occurring both further north

74 and south (at Gungo) of Kumbira Forest, while Pulitzer Longbill and Monteiro Bushshrike have

75 ranges of $c .3700 \mathrm{~km}^{2}$ and $8000 \mathrm{~km}^{2}$ respectively (Mills, 2010). Additionally, Kumbira is also

76 home to the endemic, although more widespread (c. $\left.190000 \mathrm{~km}^{2}\right)$, Red-crested Turaco Tauraco

77 erythrolophus (BirdLife International, 2015b).

78 Kumbira Forest is located in the municipality of Conda, in the western Angolan province

79 of Kwanza Sul $\left(11.107^{\circ} \mathrm{S}, 14.336^{\circ} \mathrm{E}\right)$. The exact limits of Kumbira forest are difficult to define in

80 the west, because the forest gradually merges with dense habitats associated with the escarpment.

81 The eastern limit is nevertheless clearly delimited by the grasslands of the Njelo Mountain,

82 which rises to $1,688 \mathrm{~m}$ and runs north-east/south-west. Here we define the southern limit of the

83 forest as $11.230^{\circ} \mathrm{S}$ and the northern limit as Cassungo village $\left(11.104^{\circ} \mathrm{S} 14.311^{\circ} \mathrm{E}\right)$ (Figure 1).

84 This forest represents an area of approximately 10000 ha. The terrain within this area varies

85 from relatively flat in the valley bottoms, to the steep slopes of the Njelo Mountain, with

86 altitudes varying from $c .680$ to $1,160 \mathrm{~m}$ asl.

88 Bird Data

89 MSLM sampled bird communities by means of 10 min point counts (Bibby et al., 2000) from 13

90 September 2010 to 2 October 2010, between sunrise (c. 0545h) and 1030h, except when weather

91 was poor (rain or strong wind). All birds seen and heard within a $50 \mathrm{~m}$ radius of each sample

92 point were recorded. Sample points were spaced at least>150 m apart of each other to avoid 
93 double-counting individuals. Furthermore, points were located along existing paths in order to

94 sample as much of Kumbira Forest as possible in this three weeks expedition. Each 10 min point

95 count was divided into two 5 min periods. In order to map the presence of the five key species, a

96 pre-composed track consisting of 30 s snippets of the vocalisations of Monteiro's Bushshrike,

97 Red-crested Turaco, Gabela Bushshrike, Gabela Akalat and Pulitzer's Longbill) was played

98 between these two periods, to increase their detectability. Playback was done using an Ipod

99 (Apple, Cupertino) and RadioShack Mini Amplifier speaker (RadioShack Corporation, Fort

100 Worth), always at the same volume. Because playback violates the point count assumption that

101 birds do not approach the observer, we only use playback data for the analysis of species

102 presence. We also excluded all observations that could refer to birds that had already been

103 registered.

104

105 Environmental variables - ground variables recorded in situ

106 Habitat characteristics were measured by AC in a circular sample plot of $10 \mathrm{~m}$ radius around

107 each bird sample point. The variables measured were: (1) elevation (elev) by GPS; (2) canopy

108 height (ch) as the maximum visible height of the canopy (Dallimer et al., 2009), using a Nikon

109550 Laser rangefinder (Nikon Corporation, Tokyo); (3) canopy cover (cc) with a convex

110 spherical densiometer (Forestry Suppliers Inc., Jackson); (4) shrub cover (shrub) as the

111 percentage of vegetation cover at the shrub level $(0.15-1.5 \mathrm{~m})$ along a $10 \mathrm{~m}$ transect; and (5) liana

112 density (ld) as the number of lianas along a $10 \mathrm{~m}$ transect. Canopy height and canopy cover were

113 the average of four measurements taken at $5 \mathrm{~m}$ in each cardinal direction from the sample point,

114 To estimate above-ground biomass (AGB) at each plot, we measured height and diameter

115 at breast height $(\mathrm{DBH})$ of all trees with a $\mathrm{DBH}>10 \mathrm{~cm}$. Tree height was measured with a 
116 clinometer and DBH with a measuring tape. AGB was calculated using a pantropical allometric

117 equation (Chave et al., 2014) that relates AGB of a tree to DBH, total height and wood density.

118 Since it was not possible to identify the species of trees to obtain specific wood densities, we

119 applied a constant wood density of $0.59 \mathrm{~g} / \mathrm{cm} 3$, the average reported for trees in Africa (Henry et

120 al., 2010). Finally, biomass estimates were converted to carbon values using the fraction of 0.47

$121 \mathrm{MgC}$, as recommended for tropical and subtropical regions (Paustian et al., 2006), and

122 standardized per area $(\mathrm{MgC} / \mathrm{ha})$.

124 Environmental variables derived from remote sensing

125 Spectral indices and forest cover (xfor) were calculated from Landsat 7 ETM+ satellite image

126 (WRS-2 path 181 row 68) with low cloud cover $(<10 \%)$ from 18 May 2010, obtained from the

127 U.S. Geological Survey (USGS) and Earth Resources Observation \& Science Center (EROS) via

128 the EarthExplorer interface (http://earthexplorer.usgs.gov). It was radiometric normalized and

129 atmospheric corrected using Modified Dark Object Subtraction (DOS), as proposed by Chavez

130 (1996). The empty lines of the Landsat 7 scene produced by the scan failure were treated as "no

131 data" and all sample points located in these gaps were excluded from analyses.

132 The following spectral indices were calculated for a $50 \mathrm{~m}$ radius circular plot around each

133 bird sample point: (1) Land Surface Water Index (LSWI), calculated as the normalized

134 proportion between Near Infrared (NIR) and Short Wave Infrared (SWIR), represents the amount

135 of moisture present in the leaves and soil (Xiao et al., 2002); (2) Blue-Red ratio Index (BR) that

136 is the normalized difference between the Blue and Red bands and represents the shadow

137 produced by the canopy; and (3) Enhanced Vegetation Index (EVI) that optimizes vegetation

138 signal in regions with high biomass and reduces atmosphere influences (Huete et al., 2002). 
140 Likelihood Algorithm (MLA) (Jensen, 2005). The scene was classified in "Forest" and "Non-

141 Forest" with Regions of Interest chosen based on field knowledge of the study area. Accuracy of

142 the forest class was assessed by comparing the resulting classification with Google Earth high

143 resolution images. Based on this information we estimated the forest cover percent in a $50 \mathrm{~m}$

144 radius circular plot around each bird sample point.

146 Data Analysis

147 Generalized Linear Models (GLM) (Nelder and Wedderburn, 1972) were used to evaluate bird

148 responses to environmental variables (Zuur et al., 2007) (Supplementary material, Table S1).

149 Bird responses were represented by species richness and by the presence of endemic species that

150 were recorded in over 20 percent of the point counts, namely Red-crested Turaco, Gabela Akalat

151 and Gabela Bushshrike. All variables were standardized and collinearity was assessed by

152 Spearman rank correlation coefficients, which does not assume linear relations between

153 variables. Variables with coefficients of over 0.7 were removed from the analyses (Zuur et al.,

154 2009). The variables maintained in the analyses were chosen based on their biological

155 importance and management relevance. We also assessed spatial autocorrelation using Pearson-

156 based Mantel tests (Legendre and Legendre, 1998) with 1000 permutations and mapping the

157 residuals of the best ranking models (Baddeley et al., 2005, Kühn and Dormann, 2012). All these

158 analyses were carried out for each of the response variables (species richness and the presence of

159 endemics).

160 To assess whether remote sensing variables (spectral indices and forest cover) provided

161 additional information for modelling bird diversity in Kumbira, we modelled species richness 
162 and the endemic species presence using a dataset with remote sensing and ground variables.

163 Then, we identified the best models for each group of variables: (1) the "null model" (with no

164 explanatory variables); (2) only ground (hereafter "Ground Models"); (3) only remote sensing

165 (hereafter" RS Models"); and (4) ground and remote sensing (hereafter "Combined Models").

166 Only sample points that had both spectral indices and forest cover estimates were used in

167 the analyses - those affected by Landsat 7 scan failure were excluded. Model performance was

168 evaluated using Akaike's Information Criterion with small sample size correction (AICc),

169 Akaike weights $(\omega)$ and evidence ratio (Hurvich and Tsai, 1989, Anderson and Burnham, 2002,

170 Burnham and Anderson, 2002, Burnham and Anderson, 2004).

171 To assess the environmental variables driving bird diversity at Kumbira Forest, GLMs

172 were constructed with the larger dataset that included only the ground variables of all the sample

173 points $(\mathrm{N}=201)$. An adjusted coefficient of determination was used $\left(\mathrm{R}^{2}\right)$ to assess the predictive

174 power of the models. Model averaging was performed to obtain coefficients estimates for all

175 models with a AICc difference ( $\triangle \mathrm{AICc}$ ) smaller than 10 (Burnham and Anderson, 2002,

176 Burnham et al., 2011). Plotting of coefficients estimates and standard errors were used to identify

177 key variables, and their relative variable importance (RVI) was also calculated. All analyses

178 were performed using R 3.2.0 software (R Core Team, 2015) and the packages Vegan 2.0-9

179 (Oksanen et al., 2012) and MuMIn 1.9.13 (Barton, 2013).

180

\section{Results}

182 A total of 201 bird point counts were performed and 100 bird species registered. The mean

183 species richness per point count was $10.4 \pm 3.4$ species (mean \pm standard deviation) with a range

184 from one to 23 species. Red-crested Turaco was the most-registered endemic, recorded at 68 
185 percent of the point counts $(n=136)$, followed by Gabela Akalat $(46 \%, n=92)$ and Gabela

186 Bushshrike (21\%, n=42). Monteiro Bushshrike and Pulitzer Longbill were present only in 7

187 percent $(n=15)$ and 5 percent $(n=11)$ of the point counts respectively. Vegetation characteristics

188 were measured for all the sample points but spectral indices (LSWI, EVI and BR) and forest

189 cover were only estimated for 132 out of 201 points due to the Landsat 7 scan failure (Figure 2).

Figure 2

190 Canopy height was strongly correlated with canopy cover (cor=0.70, $p$-value $<0.001$ )

191 and thus excluded from the analysis, as was blue-red ratio with forest cover (cor=0.73, $p$-value <

192 0.001) (Supplementary material, Figure S1). Both canopy cover and forest cover were retained

193 for analyses because of their importance for species richness and Gabela Akalat presence, and

194 their relevance to forest management.

195

196 Spatial autocorrelation

197 Only the Mantel test for the presence of Red-crested Turaco showed a weak but significant

198 degree of spatial correlation $(\mathrm{r}=0.04, \mathrm{P}=0.032)$ while in the other response variables the test was

199 not significant ( species richness $\mathrm{r}=-0.05, \mathrm{P}=0.951$; Gabela Akalat $\mathrm{r}=0.007, \mathrm{P}=0.147$; Gabela

200 Bushshrike $\mathrm{r}=-0.02, \mathrm{P}=0.703$ ) (Supplementary material, Table S2). However, the residual

201 plots did not show any clear pattern of the models residuals (Supplementary material, Figure S2).

202

203

Effects of remote sensing variables

204 Only in the case of species richness, Combined Models greatly outperformed both RS Models

205 and Ground Models, as shown by the high evidence ratios (29.2 and 118.4 respectively, Table 1).

206 RS Models were good in predicting the presence of Gabela Akalat and performed even better 
207 when combined with ground variables. Nevertheless, RS Models performed poorly for the

208 presence of Red-crested Turaco and Gabela Bushshrike, as they ranked below the null models.

210 Role of habitat characteristics in determining bird diversity in Kumbira

211 Canopy cover positively influenced species richness and the presence of Gabela Akalat, while

212 liana density positively influenced species richness and Red-crested Turaco presence. Elevation Table 2

213 had a negative influence in Gabela Bushshrike and a positive in Red-crested Turaco (Table2,

214 Figure 3). Despite the influence of these variables on the models, they still presented high levels Figure 3

215 of unexplained variation as shown by the low values of their adjusted coefficients of

216 determination (Supplementary material, Table S3 - Table S6).

218 Discussion

219 The use of remotely sensed data is becoming more widespread in conservation planning. Spectral

220 indices and classification maps are often used to infer habitat suitability and examine

221 environmental drivers of biodiversity (Huete et al., 2002, Pettorelli et al., 2005). However, we

222 demonstrate here that the utility of this approach is rather limited and species specific for the

223 Angolan Central Escarpment. For example, RS models performed very poorly in explaining the

224 presence of Red-crested Turaco and Gabela Bushshrike, being even outperformed by null 225 models.

226 The limited predictive performance of models based on Landsat imagery is not entirely

227 surprising. While Landsat imagery can be used well over long temporal and large spatial scales

228 (Kerr and Ostrovsky, 2003, Wang et al., 2010), it is less useful for biodiversity studies conducted

229 at smaller scales and in more complex environments (Aplin, 2005, Nagendra and Rocchini, 
230 2008) - like the mosaic like and dynamic Kumbira Forest - where spectral indices not always

231 directly relate to wildlife presence or abundance (Nagendra, 2001). Furthermore, the approach

232 was also limited by the lack of adequate Landsat images due high cloud cover in the study area

233 for most of the year.

234 Remote sensing variables did provide a good approximation for some ground variables.

235 For example, forest cover (remote sensing) was correlated with canopy cover (vegetation survey)

236 (cor=0.6, $p$-value $<0.001$ ) and positively influenced bird species richness and Gabela Akalat

237 presence. This is encouraging, as variables derived from remote sensing are easier, faster and

238 cheaper to collect than most field-collected ground data, and they can be extrapolated across a

239 larger area to assess the presence of key species.

240 The poor performance of remote sensing variables for Red-crested Turaco and Gabela

241 Bushshrike can be related with satellite imagery resolution and scale issues. Despite the $30 \mathrm{~m}$

242 resolution of Landsat imagery, the variables obtained from them do not seem to detect the

243 characteristics affecting these birds. These species territories might include more of the mosaic-

244 like landscape of Kumbira, where small spatial changes might not to be detected by the Landsat

245 images.

246 Environmental variables collected in situ - elevation, canopy cover, shrub cover, liana

247 density and carbon - seem to be good predictors of bird diversity in Kumbira but even the best

248 models had high levels of unexplained variation and the variables presented a low explanatory

249 power. This can be related with the lack of statistical power due to the low detectability of some

250 endemics (present just in $20 \%$ of the sample points), or the failure of the vegetation surveys to

251 record the habitat characteristics that are driving bird diversity. 
253 endemics. Canopy cover is indirectly related to habitat disturbance and affect the presence of

254 birds, especially forest specialists (Mammides et al., 2015). This can explain its influence in

255 Gabela Bushshrike and especially Gabela Akalat. In other areas of Africa, the presence of

256 threatened endemic forest birds is also related to canopy cover and structure (Dallimer and King,

257 2007, Dallimer et al., 2012, de Lima et al., 2013, Mammides et al., 2015). Canopy cover was

258 also highly correlated with canopy height, therefore the endemics might also be affected by

259 canopy height and other aspects of mature forests including canopy structure and understorey

260 humidity.

261 Liana density was also an important variable. Lianas usually increase in gap areas or as

262 part of the successional process of secondary growth (Schnitzer and Bongers, 2002). However,

263 due to the history of human disturbance in Kumbira (transformation of natural forest to shade

264 coffee plantation), it is possible that liana presence here is indicative of older and more natural

265 forest - as lianas can only grow if there are trees in the first place - rather than areas frequently

266 disturbed mainly by slash-and-burn agriculture. This is supported by the positive associations

267 between liana density and canopy height (cor=0.37, p-value<0.001).t.

\section{Conservation Implications}

270 Our study provides some important insights into the conservation of one of Africa's critical

271 priority areas for bird conservation. Many of the results indicate that conservation efforts should

272 focus on the maintenance of canopy cover by protecting the remaining forest. For example,

273 canopy cover affects both overall species richness and the Gabela Akalat presence. The

274 endangered Gabela Akalat is the key priority for conservation at Kumbira because is the most 
275 range-restricted of the Angolan endemics with an estimated suitable range of only $c .650 \mathrm{~km}^{2}$

276 (Mills, 2010). As a result, this species is particularly sensitive to forest loss and depends in the

277 maintenance of canopy cover at Kumbira for its survival.

278 Protecting high quality mature forest in the region is challenging as the extent and

279 condition of forests are threatened by slash-and-burn agriculture and logging of high canopy

280 trees for timber (Mills, 2010, Cáceres et al., 2015). Protected areas are widely used in

281 conservation, but at present no area of the Angolan Central Escarpment Forest has formal

282 protection status. A proposal for the establishment of a $c .50 \mathrm{~km}^{2}$ strict nature reserve was put

283 forward in the past (Huntley and Matos, 1994) but has yet to be implemented. Alternative

284 approaches to protected areas could involve local populations. These include increasing forest

285 cover through reforestation initiatives, with native tree species. Such action has recently been

286 initiated in Kumbira with the establishment of an experimental nursery as part of a project

287 funded by the Conservation Leadership Programme. Wildlife friendly agriculture may also be

288 beneficial (Gove et al., 2008, Buechley et al., 2015). In this context, we recommend prioritising

289 research into the economic viability of recovering the abandoned shade coffee plantations and on

290 the impacts such action could have on biodiversity, together with the evaluation of other more

291 biodiversity-friendly agricultural practices.

292 Any conservation actions require good baseline data on the occurrence of the most

293 important species. For most species, our study demonstrates the importance of basing this on

294 good quality data from ground surveys, complemented by remote sensing variables. However, it

295 is encouraging that the presence of the most endangered species, the Gabela Akalat, can be

296 predicted by remote sensing variables, as this provides hope that large-scale mapping can be

297 used to identify priority areas. However, the models we present here had very low explanatory 
298 power, indicating the role of unmeasured factors such as landscape context and resource

299 availability. Some of these may be resolved by using newer and more refined remotely sensed

300 measures, which would also provide a basis to examine other areas of the Angolan Central

301 Escarpment Forest, such as the forest of Bango-Seles $25 \mathrm{~km}$ to the South. In addition, future

302 research should aim at including other taxa such as plants, amphibians and insects that may be

303 more sensitive to human disturbance and may not reflect the patterns of bird diversity (Kremen

304 et al., 2008). This information is critically important to enable the effective conservation and

305 sustainable planning that are required to protect the unique biological richness of this region.

\section{Acknowledgements}

308 Special thanks to Phil Hall, Nigel Collar, Brian Huntley, Michael Rogerson, Francisco Maiato and 309 Fernanda Lages. Also thank you to Ricardo Solar and Paulo Cardoso for their help with part of

310 the statistics. Antonio Monteiro collaborated in estimating the spectral indexes. This scientific

311 paper is from the Portuguese-Angolan TwinLab established between CIBIO-InBIO and

312 ISCED/Huíla, Lubango.

313

314 Financial support

315 This research was funded by the Conservation Leadership Programme (Grant 0109710) and Mr

316 A. P. Leventis of the A. P. Leventis Ornithological Research Institute, Jos, Nigeria. AC is funded

317 by a PhD grant from the Portuguese Science and Technology Foundation, FCT

318 (SFRH/BD/78778/2011). MM and RL are funded by FCT Post-Doctoral grants

319 (SFRH/BPD/100614/2014 and SFRH/BPD/91494/2012, respectively). 


\section{References}

322 Anderson, D. R. \& Burnham, K. P. 2002. Avoiding pitfalls when using information-theoretic methods. The Journal of Wildlife Management, 66: 912-918.

324 Aplin, P. 2005. Remote sensing:ecology. Progress in Physical Geography, 29: 104-113.

325 Baddeley, A., Turner, R., Moller, J. \& Hazelton, M. 2005. Residual analysis for spatial point processes. Journal of the Royal Statistical Society Series B-Statistical Methodology, 67: 617-651.

Barton, K. 2013. MuMin: Multi-model inference. R package. Vol. 1.9.13.

329

Bibby, C., Burgess, N., Hill, D. \& Mustoe, S. (2000) Bird Census Techniques: London Academic Press.

BirdLife International. 2015a. Endemic Bird Area factsheet: Western Angola.

BirdLife International. 2015b. IUCN Red List for birds.

Bradshaw, C. J. A., Sodhi, N. S. \& Brook, B. W. 2009. Tropical turmoil: a biodiversity tragedy in progress. Frontiers in Ecology and the Environment, 7: 79-87.

Brooks, T. M., Mittermeier, R. A., Mittermeier, C. G., Rylands, A. B., Konstant, W. R., Flick, P., Pilgrim, J. D., Oldfield, S., Magin, G. \& Hilton-Taylor, C. 2002. Habitat Loss and Extinction in the Hostspots of Biodiversity. Conservation Biology, 16: 909-923.

Buechley, E. R., Sekercioglu, Ç., Atickem, A., Gebremichael, G., Ndungu, J. K., Mahamued, B. A., Beyene, T., Mekonnen, T. \& Lens, L. 2015. Importance of Ethiopian shade coffee farms for forest bird conservation. Biological Conservation, 188: 50-60.

Burnham, K. P. \& Anderson, D. R. (2002) Model selection and multimodel inference: A practical information-theoretic approach, New York: Springer-Verlag. 
343 Burnham, K. P. \& Anderson, D. R. 2004. Understanding AIC and BIC in model selection.

$344 \quad$ Sociological Methods and Research, 33: 261-304.

345 Burnham, K. P., Anderson, D. R. \& Huyvaert, K. 2011. AIC model selection and multimodel

346 inference in behavioral ecology: some background, observations and comparisons. Behav

347 Ecol Sociobiol, 63: 23-35.

348 Cáceres, A., Melo, M., Barlow, J., Cardoso, P., Maiato, F. \& Mills, M. 2015. Threatened birds of 349 the Angolan Central Escarpment: distribution and response to habitat change at Kumbira $350 \quad$ Forest. Oryx, 49: $727-734$.

351 Chave, J., Réjou-Mechain, M., Búrquez, A., Chidumayo, E., Colgan, M. S., Delitti, W. B. C., Duque, A., Eid, T., Fearnside, P. M., Goodman, R. C., Henry, M., Martinez-Yrizar, A., Mugasha, W. A., Muller-Landau, H., Mencuccini, M., Nelson, B. W., Ngomanda, A., Nogueira, E. M., Ortiz-Malavassi, E., Pélissier, R., Ploton, P., Ryan, C. M., Saldarriaga, J. G. \& Vielledent, C. 2014. Improved allometric models to estimate aboveground biomass

357 Chavez, P. S. 1996. Image-based atmospheric corrections revisited and improved.

$358 \quad$ Photogrammetric Engineering and Remote Sensing, 62: 1025-1036.

359 Chazdon, R. L., Peres, C. A., Dent, D., Sheil, D., Lugo, A. E., Lamd, D., Stork, N. E. \& Miller, S.

360 E. 2009. The Potential for Species Conservation in Tropical Secondary Forests.

361 Conservation Biology, 23: 1406-1417.

362 Cincotta, R., Wisnewski, J. \& Engelman, R. 2000. Human population in the biodiversity hotspots. $363 \quad$ Nature, 404: 990-992.

364 Collar, N. J. \& Stuart, S. N. (1988) Key forests for threatened birds in Africa: Cambridge:

365 International Council for Bird Preservation. 
366 Dallimer, M. \& King, T. 2007. Habitat preferences of the forest birds on the island of Príncipe, 367 Gulf of Guinea. African Journal of Ecology, 46: 258-266.

368 Dallimer, M., King, T. \& Atkinson, R. J. 2009. Pervasive threats within a protected area:

369 conserving the endemic birds of São Tomé, West Africa. Animal Conservation, 12: 209$370 \quad 219$.

371 Dallimer, M., Parnell, M., Bicknell, J. E. \& Melo, M. 2012. The importance of novel and 372 agricultural habitats for the avifauna of an oceanic island. Journal for Nature

374 de Lima, R., Dallimer, M., Atkinson, P. W. \& Barlow, J. 2013. Biodiversity and land-use change: 375 understanding the complex responses of an endemic-rich bird assemblage. Diversity and $376 \quad$ Distributions, 19: 411-422.

377 Dean, W. R. J. 2001. Angola. In Important Birds Areas in Africa and associated islands: Priority 378 sites for conservation. (eds. L. D. C. Fishpool \& M. I. Evans), pp. 71-91. Newbury and Cambridge, UK: Pisces Publications and BirdLife International.

380 Gardner, T., Barlow, J., Chazdon, R., Ewers, R., Harvey, C., Peres, C. \& Sodhi, N. 2009. Prospects for tropical forest biodiversity in a human-modified world. Ecology Letters, 12: $561-582$.

383 Gardner, T., Barlow, J., Sodhi, N. \& Peres, C. 2010. A multi-region assessment of tropical forest 384 biodiversity in a human-modified world. Biological Conservation, 143: 2293-2300.

385 Gibson, L., Ming Lee, T., Pin Koh, L., Brook, B. W., Gardner, T. A., Barlow, J., Peres, C. A., 386 Bradshaw, C. J. A., Laurance, W. F., Lovejoy, T. E. \& Sodhi, N. S. 2011. Primary forests 387 are irreplaceable for sustaining tropical biodiversity. Nature, 478: 378-381. 
Gove, A., Hylander, K., Nemomisa, S. \& Shimelis, A. 2008. Ethiopian coffee cultivationImplications for bird conservation and environmental certification. Conservation Letters, 1: 208-216.

Hall, B. P. 1960. The faunistic importance of the scarp in Angola. Ibis, 102: 420-442.

Hawkins, F. 1993. An integrated biodiversity conservation project under development: the ICBP Angola scarp project. In Proceedings of the 8th Pan-African Ornithological Congress. (ed. R. Wilson), pp. 279-284. Tervuren: Annales Musée Royal de l'Afrique Centrale

Henry, M., Besnard, A., Asante, W. A., Eshun, J., Adu-Bredu, S., Valentini, R., Bernoux, M. \& (Zoologie).

Huete, A., Didan, K., Miura, T., Rodriguez, E. P., Gao, X. \& Ferreira, L. G. 2002. Overview of the radiometric and biophysical performance of the MODIS vegetation indices. Remote Sensing of Environment, 83: 195-213.

403 Huntley, B. J. 1974. Outlines of wildlife conservation in Angola. Journal of the South African Wildlife Management Association, 4: 157-166.

405 Huntley, B. J. \& Matos, E. M. 1994. Botanical diversity and its conservation in Angola. Strelitzia, 1: $53-74$.

Hurvich, C. M. \& Tsai, C.-L. 1989. Regression and time series model selection in small samples. Biometrika, 79: 297-307. 
411 Kerr, J. T. \& Ostrovsky, M. 2003. From space to species: ecological applications for remote $412 \quad$ sensing. Trends in Ecology \& Evolution, 18: 299-305.

413 Kremen, C., Cameron, A., Moilanen, A., Phillips, S. J., Thomas, C. D., Beentje, H., Dransfield, J., 414 Fisher, B. L., Glaw, F., Good, T. C., Harper, G. J., Hijmans, R. J., Lees, D. C., Louis, E., 415 Nussbaum, R. A., Raxworthy, C. J., Razafimpahanana, A., Schatz, G. E., Vences, M., 416 Vieites, D. R., Wright, P. C. \& Zjhra, M. L. 2008. Aligning conservation priorities across 417 taxa in Madagascar with high-resolution planning tools. Science, 320: 222-226.

418 Kühn, I. \& Dormann, C. F. 2012. Less than eight (and a half ) mis- conceptions of spatial 419 analysis. Journal of Biogeography, 39: 995-998.

420 Legendre, P. \& Legendre, L. (1998) Numerical Ecology, Amsterdam: Elsevier Scientific $421 \quad$ Publising Company.

422 Mammides, C., Schleuning, M., Bohning-Gaese, K., Schaab, G., Farwing, N., Kadis, C. \& 423 Coulson, T. 2015. The indirect effects of habitat disturbance on bird communities in a $424 \quad$ tropical African forest. Biodiversity Conservation, 24: 3083-3107.

425 Mills, M. 2010. Angola's central scarp forests: patterns of bird diversity and conservation threats. 426 Biodiversity and Conservation, 19: 1883-1903.

427 Myers, N., Mittermeier, R. A., Mittermeier, C. G., da Fonseca, G. A. B. \& Kent, J. 2000.

428 Biodiversity hotspots for conservation priorities. Nature, 403: 853-858.

429 Nagendra, H. 2001. Using remote sensing to assess biodiversity. International Journal of Remote $430 \quad$ Sensing, 22: 2377-2400.

431 Nagendra, H. \& Rocchini, D. 2008. High resolution satellite imagery for tropical biodiversity 432 studies: the devil is in the detail. Biodiversity \& Conservation, 17: 3431-3442. 
433 Nelder, J. A. \& Wedderburn, R. W. M. 1972. Generalized Linear Models. Journal of the Royal $434 \quad$ Statistical Society. Series A (General), 135: 370-384.

435 Norris, K., Asase, A., Collen, B., Gockowski, J., Mason, J., Phalan, B. \& Wade, A. 2010.

436 Biodiversity in a forest-agriculture mosaic - The changing face of West African 437 rainforests. Biological Conservation, 143: 2341-2350.

438 Oksanen, J., Blanchet, G. F., Kindt, R., Legendre, P., Minchin, P. R., O'Hara, R. B., Simpson, G.

439 L., Solymos, P., Stevens, H. H. \& Wagner, H. 2012. Vegan: Community Ecology $440 \quad$ Package. $\mathrm{R}$ package version 2.0-5.

441 Paustian, K., Ravindranath, N. H. \& Van Amstel, A. 2006. Agriculture, Forestry and Other Land 442 Use. In 2006 IPCC Guidelines for National Greenhouse Gas Inventories. . (eds. H. S.

443 Eggleston, L. Buendia, K. Miwa, T. Ngara \& K. Tanabe), pp. 448. Tokyo, Japan: National $444 \quad$ Greenhouse Gas Inventories Programm.

445 Pettorelli, N., Olav Vik, J., Mysterud, A., Gaillard, J.-M., Tucker, C. J. \& Stenseth, N. C. 2005.

446 Using the satellite-derived NDVI to assess ecological responses to environmental change. $447 \quad$ Trends in Ecology \& Evolution, 20: 503-510.

448 R Core Team. 2015. R: A language and environment for statistical computing. (ed. R. F. f. S. 449 Computing). Vienna, Austria.

450 Ryan, P. G., Sinclair, I., Cohen, C., Mills, M., Spottiswoode, C. \& Cassidy, R. 2004. The 451 conservation status and vocalizations of threatened birds from the scarp forest of the 452 Western Angola Endemic Area. Bird Conservation International, 14: 247-260.

453 Schnitzer, S. A. \& Bongers, F. 2002. The ecology of lianas and their role in forests. Trends in $454 \quad$ Ecology \& Evolution, 17: 223-230. 
Schulze, C. H., Waltert, M., Kessler, P. J. A., Pitopang, R., Shahabuddin, Dorthe, V., Mühlenberg, M., Gradstein, S. R., Leuschner, C., Steffan-Dewenter, I. \& Tscharntke, T. 2004. Biodiversity indicator groups of Tropical land-use systems: comparing plants, birds, and insects. Ecological Applications, 14: 1321-1333.

459 Sekercioglu, Ç. \& Riley, A. 2005. A brief survey of the birds in Kumbira Forest, Gabela, Angola. $460 \quad$ Ostrich, 76: 111-117.

461 Stattersfield, A. \& Capper, D. (2000) Threatened Birds of the World: Lynx Edicions.

462 USAID. 2008. Biodiversity and Tropical Forest Asssessment for Angola.

463 Wang, K., Franklin, S. E., Guo, X. \& Cattet, M. 2010. Remote sensing of ecology, biodiversity and conservation: a review from the perspective of remote sensing specialists. Sensors, 10: 9647-9667.

Xiao, X., Boles, S., Frolking, S., Salas, W., Moore III, B., Li, C., He, L. \& Zhao, R. 2002. Observation of flooding and rica transplatting of paddy rice fields at the site to landscape scales in China using vegetation sensor data. International Journal of Remote Sensing, 23:

470 Zuur, A. F., Ieno, E. N. \& Smith, G. M. (2007) Analysing Ecological Data, New York: SpringerVerlag.

472 Zuur, A. F., Ieno, E. N., Walker, N. J., Saveliev, A. A. \& Smith, G. M. (2009) Mixed Effects 


\section{TABLES}

477 Table 1. Best models generated for each group of variables (N null, G ground, RS remote sensing, and G+RS combined) for species

478 richness and the presence of Red-crested Turaco, Gabela Akalat and Gabela Bushshrike. The rank of each model is included (from

479256 possible models), followed by the variables included in each model, the model log-likelihood (logLik), the number of parameters

480 (K), the Akaike's Information Criterion with small sample size correction (AICc), AIC differences $(\triangle \mathrm{AICc})$, Akaike weights $(\omega)$ and

481 evidence ratio. The variables used were EVI - enhanced vegetation index, LSWI - land-surface water index, xfor - forest cover, c -

482 carbon, cc - canopy cover, elev - elevation, ld - liana density and shrub - shrub cover.

\begin{tabular}{|c|c|c|c|c|c|c|c|c|c|}
\hline Response Variable & $\begin{array}{l}\text { Variable } \\
\text { groups }\end{array}$ & $\begin{array}{l}\text { Model } \\
\text { rank \# }\end{array}$ & Variables in model & logLik & $\mathrm{K}$ & AICc & $\triangle \mathrm{AlCc}$ & $\omega$ & $\begin{array}{c}\text { Evidence } \\
\text { ratio }\end{array}$ \\
\hline \multirow[t]{4}{*}{ Species Richness } & $G+R S$ & 1 & Id, xfor & -174.53 & 3 & 357.38 & 0.00 & 0.1113 & \\
\hline & RS & 56 & xfor & -178.97 & 2 & 364.13 & 6.75 & 0.0038 & 29.2 \\
\hline & $\mathrm{G}$ & 97 & cc, Id & -179.31 & 3 & 366.93 & 9.55 & 0.0009 & 118.4 \\
\hline & $\mathrm{N}$ & 246 & & -186.80 & 1 & 377.69 & 20.31 & 0.0000 & 25714.8 \\
\hline \multirow[t]{4}{*}{ Red-crested Turaco } & $\mathrm{G}$ & 1 & elev, Id & -82.66 & 3 & 171.50 & 0.00 & 0.0319 & \\
\hline & $\mathrm{G}+\mathrm{RS}$ & 3 & c, elev, Id, xfor & -80.78 & 5 & 172.03 & 0.53 & 0.0245 & 1.3 \\
\hline & $\mathrm{N}$ & 26 & & -85.95 & 1 & 173.93 & 2.42 & 0.0095 & 3.4 \\
\hline & RS & 41 & xfor & -85.35 & 2 & 174.79 & 3.28 & 0.0062 & 5.2 \\
\hline \multirow[t]{4}{*}{ Gabela Akalat } & $\mathrm{G}+\mathrm{RS}$ & 1 & c, EVI, xfor & -84.15 & 4 & 176.61 & 0.00 & 0.0490 & \\
\hline & $\mathrm{RS}$ & 3 & xfor & -86.71 & 2 & 177.51 & 0.90 & 0.0312 & 1.6 \\
\hline & $\mathrm{G}$ & 38 & $\mathrm{C}, \mathrm{CC}$ & -87.14 & 3 & 180.46 & 3.85 & 0.0071 & 6.9 \\
\hline & $\mathrm{N}$ & 87 & & -89.97 & 1 & 181.98 & 5.37 & 0.0033 & 14.7 \\
\hline \multirow[t]{4}{*}{ Gabela Bushshrike } & $\mathrm{G}$ & 1 & elev, Id & -65.88 & 3 & 137.95 & 0.00 & 0.0528 & \\
\hline & $\mathrm{G}+\mathrm{RS}$ & 2 & elev, Id, xfor & -64.97 & 4 & 138.25 & 0.30 & 0.0455 & 1.2 \\
\hline & $\mathrm{N}$ & 70 & & -70.75 & 1 & 143.52 & 5.57 & 0.0033 & 16.2 \\
\hline & RS & 111 & xfor & -70.42 & 2 & 144.93 & 6.98 & 0.0016 & 32.7 \\
\hline
\end{tabular}


Table 2. Relative variable importance (RVI) and averaged coefficients estimates obtained from generalised linear models with ground variables (c - carbon, cc - canopy cover, elev elevation, ld - liana density, shrub - shrub cover) for species richness and the presence of Redcrested Turaco, Gabela Akalat and Gabela Bushshrike. Only models with $\triangle$ AICc $<10$ were included in the analysis. The grey shading highlights variables with the highest relative importance values $(>0.5)$ and the asterisks indicate significance levels for $p$-value $(*)<0.05$, $(* *)<0.01$, and $(* * *)<0.001$.

\begin{tabular}{|c|c|c|c|c|c|c|c|c|}
\hline & \multicolumn{2}{|c|}{ Species Richness } & \multicolumn{2}{|c|}{ Red-crested Turaco } & \multicolumn{2}{|c|}{ Gabela Akalat } & \multicolumn{2}{|c|}{ Gabela Bushshrike } \\
\hline & RVI & Coef. & RVI & Coef. & $\mathrm{RVI}$ & Coef. & RVI & Coef. \\
\hline c & 0.268 & 0.025 & 0.679 & -0.298 & 0.349 & -0.138 & 0.362 & -0.1951 \\
\hline $\mathrm{cc}$ & 1.000 & $0.282^{\star \star \star}$ & 0.307 & 0.110 & 0.798 & $0.338^{\star}$ & 0.554 & 0.3127 \\
\hline elev & 0.299 & 0.044 & 0.992 & $-0.503^{\star \star}$ & 0.388 & 0.159 & 0.729 & $0.3512^{\star}$ \\
\hline ld & 0.992 & $0.223^{\star \star}$ & 0.883 & $0.443^{\star}$ & 0.267 & -0.016 & 0.474 & -0.276 \\
\hline shrub & 0.271 & -0.029 & 0.268 & -0.024 & 0.308 & -0.098 & 0.334 & -0.1591 \\
\hline
\end{tabular}

